\title{
Guidelines and care pathways for genetic diseases: the Scottish collaborative project on tuberous sclerosis
}

\author{
Nicola B radshaw ${ }^{1}$, Carole B rewer ${ }^{1}$, D avid FitzPatrick ${ }^{1}$, George M urray ${ }^{2}$, \\ Frances R odgers ${ }^{2}, \mathrm{M}$ ary Porteous ${ }^{1}$ and $\mathrm{H}$ arry $\mathrm{C}$ ampbell ${ }^{1}$ \\ ${ }^{1} D$ epartment of Clinical G enetics, Western G eneral H ospital, E dinburgh \\ ${ }^{2} B$ orders N etwork Team, M elrose, Scotland
}

\begin{abstract}
In Scotland a national audit project has been undertaken to devise evidencebased guidelines for the clinical management of patients with tuberous sclerosis (TS), a dominantly inherited multisystem disorder. In order to facilitate the audit and use of these guidelines a 'Care Pathway' was devised to form the patient records. We describe the process of guideline development for TS and our TS Care Pathway.
\end{abstract}

Keywords: guidelines; care pathway; audit; tuberous sclerosis

\section{Introduction}

Clinical genetics services in Scotland are available from four supra-regional centres based in, A berdeen, D undee, E dinburgh and Glasgow. Many genetic patients require multidisciplinary care and the precise nature and level of current clinical genetic involvement varies across the centres, often resulting in differing care for individuals, possibly even within a family. U se of accepted multidisciplinary guidelines common to each centre would reduce unnecessary variations in clinical practice and improve communication between professionals involved in patient care.

There is a growing call for audit to be carried out in the field of clinical genetics to ensure a continuing high standard of service. It is important that in such an expanding area of service practical and effective

Correspondence: Nicola Bradshaw, Department of Clinical G enetics, Western G eneral H ospital, C rewe R oad, E dinburgh E H 4 2X U, Scotland. Tel: 0131651 1020; Fax: 0131651 1013; E mail: nb@srvO.med.ed.ac.uk.

R eceived 5 November 1997; revised 21 January 1998; accepted 20 February 1998 processes are set in place to facilitate the development of audit. One barrier to the introduction of audit in clinical genetic service is the variable quality of patient data held in clinical records. Experience in other areas of hospital practice has shown that 'Integrated Care Pathways' provide a mechanism for the efficient capture of key data for audit purposes and for promoting the use of clinical guidelines in current practice.

In July 1996 a three-year nationwide project was initiated in Scotland. This project aims to establish evidence-based national clinical guidelines and Integrated Care Pathways for five genetic conditions tuberous sclerosis (TS), myotonic dystrophy (DM), marfan syndrome, Huntington disease (HD) and neurofibromatosis type 1 (NF 1). Together these five conditions account for $20-25 \%$ of new referrals, not including cancer, to the Scottish genetics services.

In this article we will briefly describe the experience of the Scottish Clinical Genetics Guidelines Working $G$ roup in establishing clinical guidelines and Integrated Care Pathways for the management of five genetic conditions and give details of the guidelines developed for tuberous sclerosis. 


\section{Development of clinical guidelines in Scotland}

The use of guidelines improves the service delivered to the patient and communication between professionals involved in it. ${ }^{1-3}$ Professional enquiries and searches of literature revealed there were no evidence-based guidelines published for management of any hereditary conditions. The management of patients in Scotland by the Clinical Genetics Service was known to vary throughout the country and a variety of professionals were involved in patient care. Guidelines were needed to ensure a national level of service based on current levels of evidence.

A three-year grant for the development of guidelines and care pathways was provided from the Clinical Resource and Audit Group (CRAG) of the Scottish Office. As successful completion of the project is dependent on good communication between each of the genetics centres in Scotland, a research assistant, based in Edinburgh, was employed to ensure smooth running and co-ordinate work. Each centre took responsibility for one of the five conditions, E dinburgh for two, and consensus conferences were held every six months to discuss the progress of the project.

In order to develop valid national guidelines for Scotland it is recommended that a certain process of guideline development is adhered to. We applied criteria published by the Scottish I ntercollegiate G uidelines Network (SIGN) for the development and appraisal of national guidelines. ${ }^{4}$ This method requires a systematic process of identifying and synthesising the evidence, involvement of a multidisciplinary group, including representatives from all key disciplines, and explicit links to be made between the level of evidence and recommendation. (Table 1 and Table 2)

O ur experience in Scotland has revealed that for the management of the five selected genetic conditions, limited evidence has come from randomised control trials and thus most recommendations are ' $G$ rade $C$ '. We ensured input from acknowledged experts from allied disciplines in the preparation of draft guidelines. These were then discussed at consensus conferences

Table 1 Stages in guideline development in Scotland

1 Formation of multidisciplinary team

2 Systematic review of the literature

3 Expert opinions

4 Consensus conference

$5 \mathrm{G}$ rading of recommendations

6 E stablished Scottish guidelines attended by the guideline developers and representatives from all the Scottish Clinical Genetics Centres (Appendix) before being adapted and agreed as national guidelines. Similar methods of guideline development have also been used by other guideline development groups. ${ }^{5-6}$

\section{Establishment of Integrated Care Pathways}

Integrated Care Pathways (ICPs) are structured multidisciplinary records of care which detail essential steps in the care of patients. I deally these are devised from guidelines to facilitate their use and improve ease of audit. ${ }^{7}$ I t has been shown that the use of evidence-based clinical guidelines ${ }^{1}$ and of Integrated Care Pathways ${ }^{8-9}$ can improve patient care and reduce unnecessary variations in clinical practice across different centres.

Care pathways take the form of simply structured records of care that document each step and type of intervention during a care episo de. A ny variations from the care pathway are recorded for further analysis. This will provide information on the cause and frequency of variations in patient care that can then be used for audit purposes.

It is important to determine the cause of any variation from the care pathway. Variations that are potentially avoidable can be identified and appropriate measures taken to remedy the situation. If it is found that unavoidable variations occur frequently, there may be underlying problems which also need to be addressed. A s care pathways should reflect best current practice it is likely that changes will be made representing improvements in clinical care. These may be identified through the analysis of variations or by medical advances.

Table 2 G rading of recommendations

\begin{tabular}{ll}
\hline G rade & Recommendation \\
\hline A & $\begin{array}{l}\text { R equires at least one random controlled trial as part } \\
\text { of the body of literature of overall good quality and } \\
\text { consistency addressing the specific recommendation }\end{array}$ \\
B & $\begin{array}{l}\text { R equires availability of well conducted clinical } \\
\text { studies but no randomised clinical trials on the } \\
\text { topic of recommendation }\end{array}$ \\
C & $\begin{array}{l}\text { R equires evidence from expert committee reports } \\
\text { or opinions and/or clinical experience of respected } \\
\text { authorities. Indicates absence of directly applicable } \\
\text { studies of good quality }\end{array}$ \\
\hline
\end{tabular}


In order to allow patients more involvement and control over their care and treatment, a summary sheet detailing steps in their anticipated pathway of care is made available to patients. Patients are encouraged to take an active interest in their future care.

We carried out a note review at the four regional clinical genetics centres in Scotland. This found a lack of detail on key clinical data in the clinical records and highlighted important variations in practice between centres. (Figure 1) By studying formats of care pathways already in use and applying these to the agreed Scottish Guidelines for Tuberous Sclerosis we constructed our TS Care Pathway.

Selected pages from the TS Care Pathway are shown. (Figure 2) The care path takes the form of a coloured booklet with a structure consisting of tick boxes and spaces to be filled in. The Scottish G uidelines for TS are printed on facing pages and a variation sheet at the back of the booklet gives space for recording any variations from the path and the reasons for these variations. A page is included for clinical notes. The care path should be signed and dated by the clinician and the patients name and date of consultation should be at the top of each page.

We propose to implement care pathways throughout Scotland for each of the five conditions. These pathways will augment current clinical records and provide a basis for audit of actual practice against the agreed guidelines for best practice. A $n$ initial audit will be conducted on the first year of use of each care pathway in each of the four clinical genetics centre in Scotland.

\section{Audit in Clinical Genetics}

Clinical genetics is a relatively new and fast growing area of health care. A dvances in this area are of great interest to members of the general public and the media. It is necessary to ensure that audit procedures are implemented now which will assure the public and the health authorities of the high quality of services available.

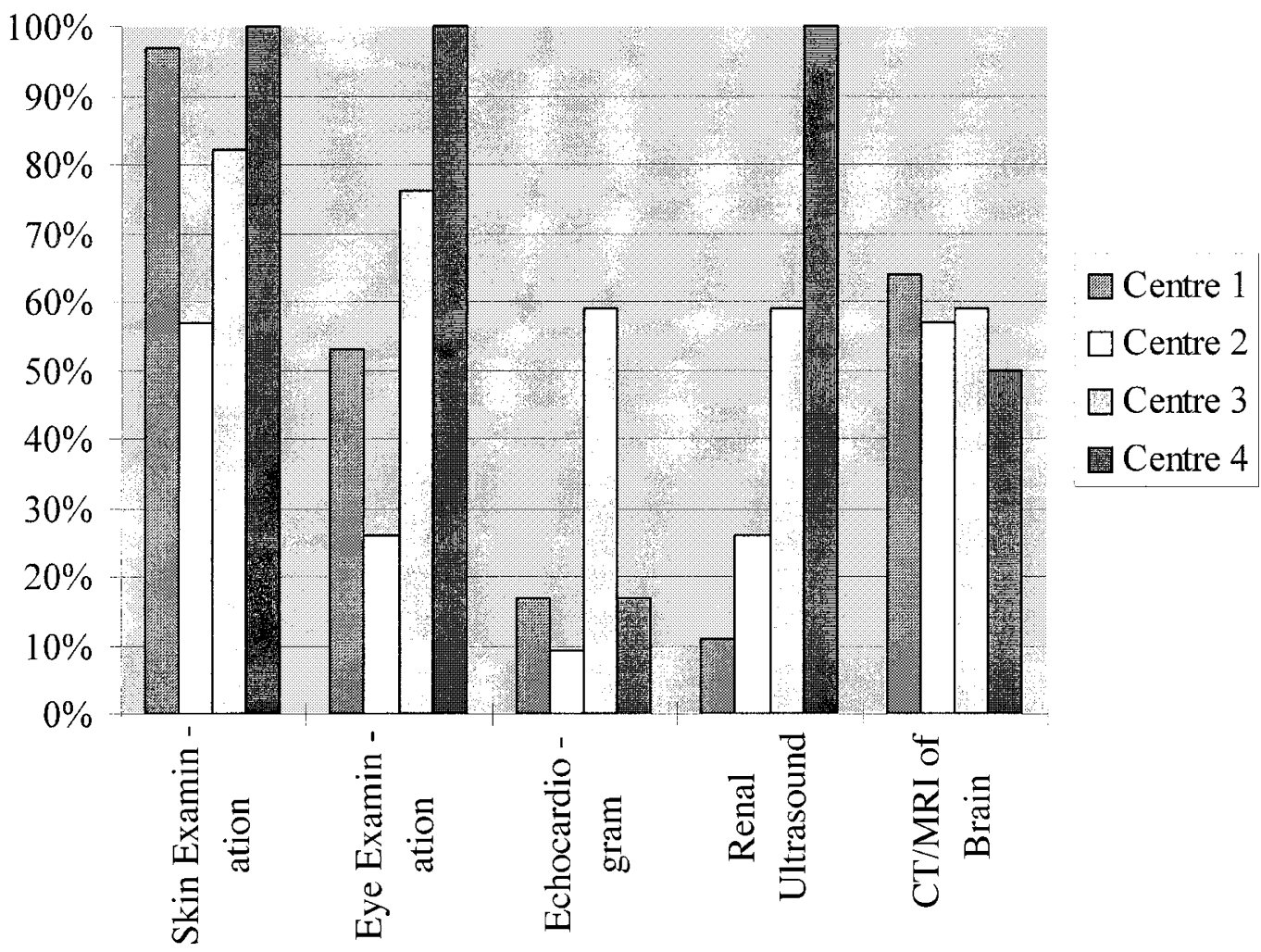

Figure 1 Investigations conducted on affected individuals (1971-1996) (CT = computed tomography; M R I =magnetic resonance imaging.) 
Date

Name

Date of Birth

Pedigree No

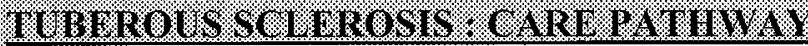

Pedigree drawn/confirmed

YES NO

COMMENTS

Reason for referral/Questions

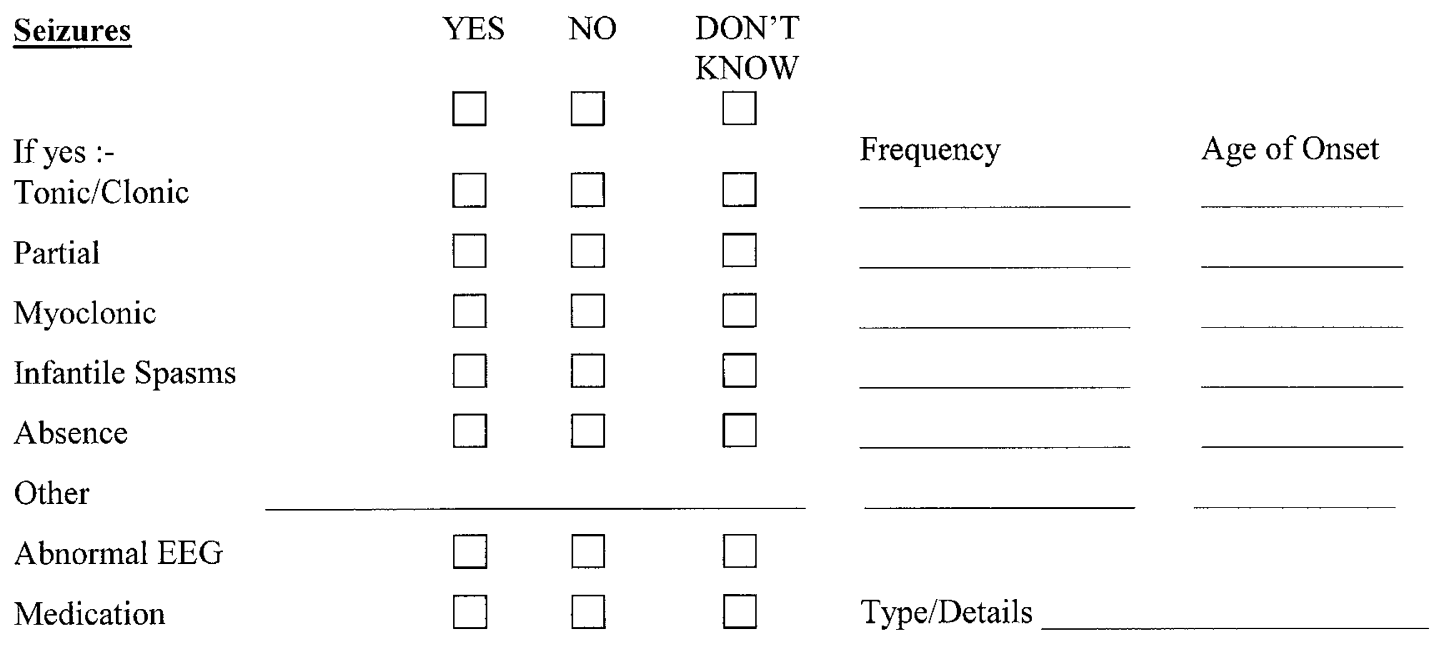

Prescribed by

Needs Further Control

Other CNS symptoms

$\square \quad \square \quad$ If yes, referred to

$\square \quad \square \quad$ Details

Changes in CNS Symptoms

Details

If yes refer for scan
COMMENTS

Figure 2 Tuberous Sclerosis Care Path form. 
Date

Name

Date of Birth

Pedigree No

Learning Disability

$\begin{array}{cc}\text { YES } & \text { NO } \\ \square & \square \\ \text { Mild/Moderate/Severe }\end{array}$

If yes-

YES NO COMMENTS

Autism

(i) communication difficulties

(ii) socialisation difficulties

(iii) obsessive/ritualistic/stereotyped behaviours

COMMENTS

\section{Attention Deficit Hyperactivity Disorder}

(i) attention/concentration difficulties

(ii) hyperactivity

(iii) impulsivity

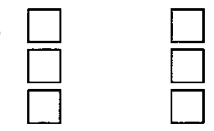

COMMENTS

\section{Sleep disturbance}

(i) settling at night

(ii) early waking

(iii) disturbance during night

(iv) no of hours of sleep

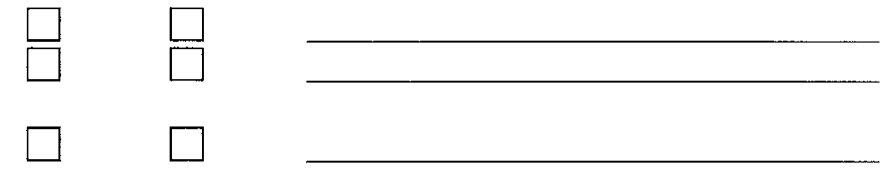

COMMENTS

\section{Other behaviour difficulties}

(i) aggressive behaviour

(ii) violent/destructive behaviour

(iii) self-injurious behaviour

(iv) inappropriate sexual behaviour

(v) withdrawn/overly passive behaviour

(vi) other

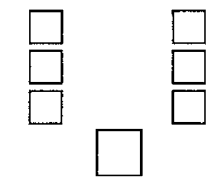


Date

Name

Date of Birth

Pedigree No

\section{$\underline{\text { Renal }}$}

Date of Renal Ultrasound

Ultrasound Results

Abnormalities detected

Presence of warning signs

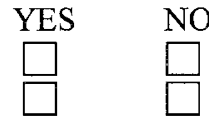

(eg haematuria, flank pain, unexplained fevers or

UTI's or anaemia)

If abnormalities detected-

Angiomyolipoma $<4 \mathrm{~cm}$

Angiomyolipoma $>4 \mathrm{~cm}$

Renal Cysts

Renal Cell Carcinoma

Other

Details

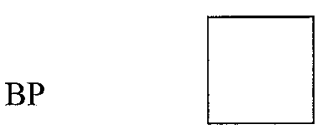

$\begin{array}{cl}\text { Creatinine } & \text { YES } \\ \square \\ \square\end{array}$

Refer to a Renal Physician

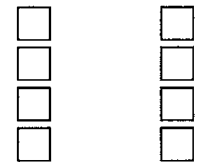

Comments

\section{NO}

Comments

Details

Details

Details

Details

\section{Next ultrasound due}

Intracranial

Baseline previous

\begin{tabular}{ll} 
& YES \\
CT \\
MRI $\square$ \\
\multicolumn{1}{c}{$\square$}
\end{tabular}

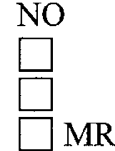

Date

If neither refer for scan

Date

Reason for choice if $\mathrm{CT}$ conducted/ referred for?

Details

\section{Findings}

Cortical Tubers

Subependymal Nodules

Giant Cell Astrocytoma

Other 
Date

Name

Date of Birth

Pedigree No

\section{Clinical Examination}

Dermatological Features

YES NO NOT

Shagreen Patch

Hypomelanic Macules

Ungual/Subungual Fibroma

$\square \quad \square$

Angiofibroma

$\square \quad \square$ If yes,

Bleeding/Disfiguring/Multiple

Forehead/Scalp Plaque

If yes, is it enlarging $\rightarrow \quad \square$ referral to dermatologist

(date)

details

COMMENTS

\section{Cardiology}

Cardiac Rhabdomyoma

YES

NO NOT EVALUATED COMMENTS

YES OK

Baseline ECG

-

YES - ABNORMAL

REQUESTED

refer to cardiology

Clinical Exam

NO PROBLEMS

PROBLEMS

COMMENTS

refer to cardiology

Refer to Cardiology

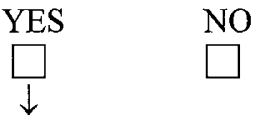

To

Figure2 Continued. 
Date

Other features

Retinal Phakoma

Lung Cysts
Name Date of Birth

Pedigree No

Clinical investigation of family members

\begin{tabular}{|c|c|c|c|c|c|c|c|}
\hline \multirow[b]{2}{*}{ Relative- } & \multicolumn{2}{|c|}{ CT/MRI } & \multicolumn{2}{|c|}{ Renal } & \multicolumn{2}{|c|}{ Clinical } & \multirow{3}{*}{ CONCLUSION } \\
\hline & Yes & No & Yes & No & Yes & No & \\
\hline & $\square$ & $\square$ & $\square$ & $\square$ & $\square$ & $\square$ & \\
\hline & $\square$ & $\square$ & $\square$ & $\square$ & $\square$ & $\square$ & \\
\hline & $\square$ & $\square$ & $\square$ & $\square$ & $\square$ & $\square$ & \\
\hline
\end{tabular}

\section{OUTCOME}

Recurrence Risk Given
UNAFFECTED/AFFECTED/NOT KNOWN

YES NO DETAILS
FOUND

SPECIALIST COMMENTS<smiles>C1=C2CC=C2CC1</smiles>

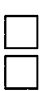

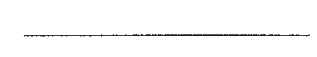


Current audit procedures involve extra tasks and work from the clinical genetics team. This can be very frustrating and time consuming. The development of guidelines and care pathways provides a method by which audit can be readily and quickly achieved. U sing the care pathway to record clinical consultations facilities transfer of information into audit reports. A nalysis of variation allows areas for improvement to be readily identified and acted upon.

\section{Tuberous Sclerosis Guidelines}

A search conducted on Medline identified 849 references on TS from the year 1980 onwards. R educing the limits on a search may have resulted in missing relevant information or recommendations contained within papers, therefore a manual search was conducted by a clinical geneticist (M P) to identify literature for review; 267 relevant papers were identified and obtained for this purpose. Six additional papers were identified during review.

The literature was split into subtopics such as intracranial scanning, nephrology, cardiology, dermatology, behaviour, epilepsy, the gastrointestinal tract, eyes, teeth, lung involvement, plus any other publications. A team from the Clinical Genetics D epartment in E dinburgh (MP, DF, CB, NB) with the help of a psychiatrist $(F R)$ and clinical psychologist $(G M)$ reviewed this literature and determined recommendations for guidelines from available evidence.

The results of this literature review indicated that there was no evidence available from randomised control trials; therefore there are no ' $G$ rade $A$ ' recommendations for the care of individuals affected with TS. $\mathrm{R}$ ecommendations for guidelines are therefore based on well conducted published clinical studies and expert opinion from both the literature and the experts in the UK. For this purpose the reviewers met a consultant renal physician (M W), a consultant paediatric neurologist (J S), TS nurses (CF and DS), a mental health nurse (PB) and written comments were obtained from a general practitioner (WT), neurologists ( $K B$ and M O'R ), a consultant dermatologist (RM) and paediatricians, psychiatrists and clinical geneticists involved with TS clinics. (JO, RM and PB). Contact was maintained throughout this process with the Tuberous Sclerosis A ssociation, and their Scottish organiser (NG) was involved at each stage.

Draft guidelines based on the evidence obtained were compiled by the reviewing team and discussed at a National Consensus Conference in Scotland. Staff from each of the four clinical genetics centres attended this meeting and the arising discussion led to the following agreed national guidelines.

Guidelines are shown in bold print and the letter in brackets refers to the grade of recommendation according to the level of evidence available (Table 2 ).

\section{Tuberous Sclerosis}

\section{How to Investigate Symptomatic Patients to Establish the Diagnosis}

Evidence in the literature recommends that investigations should be offered to parents of affected individuals for genetic counselling purposes. These well conducted studies estimate that $56-69 \%$ of cases are sporadic and the remaining cases are familial ${ }^{10-14}$ inherited in an autosomal dominant pattern. Criteria to determine diagnosis have been published. ${ }^{15-16}$

Dermatology The majority ( $>87 \%$ ) of affected individuals have depigmented maculae visible on examination of the skin by Woods L ight. ${ }^{11-13} \mathrm{U}$ ngual fibroma can occur in $3-19 \%$ of cases $^{11,14,17-18}$ and can be the only presenting sign. ${ }^{19}$

Conduct a thorough clinical examination of the skin and nails including a Woods Light examination. (B)

Intracranial E vidence suggests a CT or M R I scan of the brain should be offered as an investigation. ${ }^{12,17-26}$ Neurological involvement is found in the majority ( $>67 \%$ ) of cases of TS. ${ }^{12,14,18,27-29}$

Perform a CT or MRI scan of the brain. (B)

Renal R ecent studies of large groups of individuals with TS indicates that renal involvement can occur in approximately $60 \%$ of cases. ${ }^{30-32}$ Expert recommendations also support investigation of the kidneys by ultrasound. ${ }^{12-13,22,25-26}$

A symptomatic hepatic hamartomas were found in $23.5 \%$ of children with TS. $^{33}$ Case reports ${ }^{34-35}$ document their presence in other individuals; although not clinically significant, they may help diagnose asymptomatic individuals.

Perform a renal and liver ultrasound. (B)

Genetic Testing At the present time genetic testing for diagnosis of TS is not being carried out. When this is possible it will be included as a guideline and in the care pathway which can be easily changed to allow for new developments. 
How to Organise the Follow-up

For the investigation of individuals who have been diagnosed with TS the following are recommendations for the clinical geneticist.

Behaviour It has been shown that behaviour and sleep problems can occur in individuals with $\mathrm{TS}^{36-46}$ and this behaviour can severely disrupt the family. ${ }^{45}$ These problems and changes in behaviour may indicate an underlying physical problem. ${ }^{37-38,47} \mathrm{~A}$ behaviour checklist for the purpose of identifying and monitoring behaviour problems was designed by a clinical psychologist (GM) and psychiatrist (FR) and incorporated in the TS pathway.

(a) Conduct a baseline assessment of an individual's behaviour using the behaviour checklist at an initial consultation. In cases where an individual attends a further session at a genetics clinic the checklist could be completed for comparison purposes. (C)

(b) The clinical geneticist should maintain contact with a multidisciplinary team specialising in behavioural management, eg including a psychiatrist and psychologist. (C)

(c) 0 ffer patient a referral to the relevant multidisciplinary team or neurologist if any problems exist which require further assessment or management. (C)

Epilepsy The majority (62-97\%) of individuals with TS suffer from epilepsy at some point in their lives. ${ }^{11-12,14,17,18,28,40,48-51}$ The management of epilepsy is similar to that of individuals without TS but a gap in care was identified during the transition from paediatric to adult care.

(a) Record the type of medication the patient receives, adequacy of control and the key doctor involved in the control of epilepsy. (C)

(b) R efer individuals with epilepsy but no learning difficulty to neurologists for treatment in cases where epilepsy is not adequately controlled. If learning difficulty presents, refer to specialist epilepsy clinic. (C)

Renal Renal involvement occurs in approximately $60 \%$ of patients with $\mathrm{TS}^{30-32}$ A ngiomyolipomas (AMLs) are the commonest lesions occurring in approximately $50 \%$ of individuals with $\mathrm{TS}^{30}$ followed by renal cysts found in approximately $15-18 \%{ }^{30,52}$
There may also be a risk of renal cell carcinoma $(\mathrm{RCC}){ }^{18}$

Regular monitoring of the kidneys is indicated $^{18,20,52-62}$ and ultrasound scanning seems to be the most appropriate modality in most cases. $C T$ or $M R$ scans are advocated by some authors either regularly or as baseline investigation. There is no good evidence to support such imaging on a routine basis and therefore it should only be considered if the ultrasound gives cause for concern or is unclear. The value of ultrasounds may be maximised by using the same operator who is familiar with the type of involvement seen in kidneys of persons with TS. Treatment of large, symptomatic tumours should be conservative, eg arterial embolisation.

(a) A renal ultrasound should be carried out when the patient is $\mathbf{5}$ years old. Enquire about any warning signs - flank pain, unexpected fevers, unexplained urinary tract infections, and anaemia. (B)

(b) E nsure the ultrasound scan is repeated every 5 years. (B)

(c) If at any stage results are positive, monitor growth every 2-3 years, ultrasounds, measure blood pressure and creatinine levels. (B)

(d) If an angiomyolipoma is over $4 \mathrm{~cm}$, or fast growing, arrange yearly ultrasounds. (C)

(e) E nsure that carers are aware of warning signs flank pain, unexpected fevers, unexplained urinary tract infections, and anaemia. C arers should seek urgent medical attention if haematuria occurs. (C)

(f) $\mathrm{R}$ efer to a renal physician when renal pathology is found and raised blood pressure, creatinine, or any of the warning signs are present. (C)

Cardiology Cardiac rhabdomyoma have been shown to occur in approximately $43-66 \%$ of children with TS, but have been shown to regress and are less common in adults. ${ }^{18,62-66}$ Symptomatic individuals can present with heart failure/arrhythmia in the neonatal period. When this occurs the child receives appropriate care from a paediatrician and therefore the clinical geneticist is unlikely to have a role.

There is a possibility that individuals with TS may have a higher than population incidence of cardiac conduction pre-excitation (Wolff-Parkinson-W hite syndrome (WPW)). This can be associated with cardiac 
rhabdomyoma's and may have a role in sudden unexplained deaths in TS. ${ }^{65}$

(a) 0 ffer individuals affected with tuberous sclerosis an E CG at the initial consultation. (C)

(b) Perform a clinical examination of the heart on all affected individuals and enquire about cardiac symptoms. (C)

(c) $\mathbf{R}$ efer to a cardiologist if any positive results are found (ie if ECG, clinical examination or symptom enquiry is positive). (C)

Dematological Aspects The majority of individuals have dermatological involvement. Studies indicate that $3-19 \%$ of affected individuals have ungual fibromas, $_{1}^{11,14,17,27} \quad 42-87 \%$ have angiofibromas $^{11,14,17,18,27,28,48-49}$ and more than $64 \%$ have depigmented maculae. ${ }^{11,14,17,18,27,28,48}$ R eports of individuals having shagreen patches vary from $18-75 \%{ }^{11,14,17,18,26}$ The incidence of forehead plaques has been reported as $25 \%{ }^{23}$ Expert opinion indicated that similar scalp plaques also occur and have a tendency to grow in late adolescence.

The clinical geneticist should refer an individual to a dermatologist if

(a) there are significant numbers of periungal fibromas

(b) there are multiple angiofibroma lesions, disfiguring angiofibroma or bleeding lesions,

(c) there are enlarging scalp plaques (C).

Pulmonary Aspects Lung involvement in the form of lymphangiolyomeiomatosis is rare, less than $1 \%$, in TS. ${ }^{67-68}$ Published case reports indicate females are more likely to be affected. ${ }^{67-73}$ Lymphangiolyomeiomatosis is generally fatal and there is no good evidence for successful therapy. ${ }^{71-72}$ Therefore screening is not justified.

Patients with TS and dyspnoea or pneumothoraces should be referred to a respiratory specialist for further investigations. (C)

Intracranial Involvement A s previously indicated the majority of TS cases can have neurological involvement and there is a risk of developing a giant cell astrocytoma. ${ }^{21,74-76}$

Multidisciplinary discussion agreed that neither $\mathrm{CT}$ nor M RI are ideal for patients with TS and, as long as behaviour and fits are monitored for changes which would then lead to further investigation, no regular neuro-radiological follow up is necessary ${ }^{74,77} \mathrm{H}$ owever, each patient should have a CT/MRI carried out for baseline reference. ${ }^{21} \mathrm{C}$ arers should be made aware of warning signs, eg worsening fits, increased headaches, changes in behaviour, or nausea. Surgical removal may be indicated if lesion is symptomatic. ${ }^{76-79}$

(a) E nsure all patients with TS have had a CT or M R I scan. (B)

(b) E nsure the carer is aware of warning signs. (C)

(c) Perform a follow-up scan if there are changes in a patient's symptoms (C).

Additional Investigations A ppropriate investigations and referrals will be undertaken for any problems which arise and for which there are no guidelines, eg concern about vision would justify a referral to a specialist. These can be noted in the variations section of the care pathway.

Follow-up In the absence of other symptoms, frequency of follow-up should be decided by the guidelines for renal involvement.

Recurrence Risks Families have been described where there have been diagnostic problems. Genetic counselling should take into account the possibilities of reduced penetrance, variability, germline mosaicism and screening anomalies. ${ }^{19,22,23,25,80-81}$

If there are no diagnostic signs of the condition, parents and family members should be counselled that the recurrence risk is low.

Siblings of patients with apparently sporadic occurrences should be offered genetic counselling at the age of 18 , with screening as previously detailed, if they have features suggestive of the TS gene, eg unexplained learning difficulties or epilepsy. (C)

Children of an affected parent should be offered a skin examination, renal and liver ultrasound and cardiac ultrasound at an initial consultation. (C)

\section{Future Developments}

In order to audit the management of tuberous sclerosis, $M$ arfan syndrome, myotonic dystrophy, neurofibromatosis 1 and $\mathrm{H}$ untington disease at each of the four centres in Scotland, the use of the first year of 'care paths' will be carefully analysed. This analysis, and constant communication between the departments involved, should also indicate if clinicians are finding the guidelines and pathway feasible tools. 
Integrated Care Pathways are not envisaged as static tools; continuous monitoring of recorded variations from the pathway will allow improvements to be made. These will be constantly implemented in practice. Similarly, as advances are made in medical research, the guidelines may change and be updated.

The TS path is the first of the five Integrated Care Pathways to be introduced in Scotland. The advent of the Scottish TS Clinic, which began in January 1997 and is based in Edinburgh, made TS the ideal candidate. This pathway has now been in use since $M$ ay and has been found to be helpful in covering key clinical data, reminding staff of guidelines and improving clinicianpatient communication. These have not been a burden to complete and have provided an accurate and concise record of the consultation. Further details about guidelines and ICPS for the other conditions are available on request.

It is hoped that other Clinical G enetics D epartments and groups involved in patient management will adopt these evidence-based guidelines and the Integrated Care Pathway approach. We would like the use of these guidelines to extend to a wider area.

\section{Acknowledgements}

The work was carried out at the Department of Clinical G enetics, Western G eneral H ospital, E dinburgh.

\section{References}

1 Grimshaw J, Freemantle N, Wallace S et al: Developing and implementing clinical practice guidelines. Quality in $\mathrm{H}$ ealth Care 1995; 4: 55-64.

2 M cNicol M, Layton A, M organ G : Team working: the key to implementing guidelines. Q uality in $\mathrm{H}$ ealth Care. 1993; 2: 215-216.

3 Grimshaw J, Russell I: A chieving health gain through clinical guidelines. I. Developing scientifically sound guidelines. Quality in Health Care 1993; 2: 243-248.

4 Scottish Intercollegiate Guidelines Network: Clinical Guidelines: Criteria for A ppraisal for National U se Scottish Intercollegiate $\mathrm{G}$ uidelines N etwork: R oyal College of Physicians, E dinburgh, 1995.

5 Eccles M, Clapp Z, G rimshaw J et al: North of E ngland evidence-based guidelines development project: methods of guideline development. BMJ 1996; 312: 760-762.

6 Thomson RT, Lavender M, M adhok R: How to ensure that guidelines are effective. BM J 1995; 311: 237-242.

7 Campbell $\mathrm{H}$, Hotchkiss R, Bradshaw N, Porteous $M$ : Integrated Care Pathways. BM J 1998; 316: 133-137.

8 O gilvie-H arris DJ, Botsford DJ, Hawker RW: Elderly patients with hip fractures: Improved outcome with the use of $\mathrm{C}$ are $\mathrm{M}$ aps with high quality medical and nursing protocols. J Orthop Trauma 1993; 7: 428-437.
9 Mosher $C$, Cronk $P, K$ idd A, McCormick P, Stockton A Sulla C: U pgrading practice with critical pathways. A m J Nurs 1992; 1: 41-44.

10 Fleury P, de Groot WP, Delleman JW, Verbeeten B J r, Frankenmolen-Witkiezwicz IM: Tuberous Sclerosis: the incidence of sporadic cases versus familial cases. Brain Dev 1980; 2: 107-117.

$11 \mathrm{H}$ unt A: Tuberous Sclerosis: A survey of 97 cases. I: Seizures, pertussis immunisation and handicap. D ev M ed Child Neurol 1983; 25: 346-349.

12 Cassidy SB, Pagon R A, Pepin M, Blumhagen J D : Family studies in tuberous sclerosis. Evaluation of apparently unaffected parents. JA M A 1983; 249: 1302-1304.

13 Sampson J R, Scahill SJ, Stephenson J B, M ann L, Connor J M : G enetic aspects of tuberous sclerosis in the west of Scotland. J M ed G enet 1989; 26: 28-31.

14 A hlsen G, G illberg IC, L indblom R, G illberg C: Tuberous sclerosis in western Sweden. A population study of cases with early childhood onset. A rch Neurol 1994; 51: 76-81.

15 Roach ES, Smith M, H uttenlocher P, B hat M, A Icorn D, $\mathrm{H}$ awley $\mathrm{L}$ : D iagnostic criteria: tuberous sclerosis complex. Report of the Diagnostic Criteria Committee of the National Tuberous Sclerosis A ssociation. J Child Neurol 1992; 7: 221-224.

16 G omez M R : Phenotypes of the tuberous sclerosis complex with a revision of the diagnostic criteria. A nn N Y A cad Sci 1991; 615: 1-7.

17 Monaghan HP, K rafch BR, MacG regor DL, Fitz CR: Tuberous sclerosis complex in children. A m J D is Child 1981; 135: 912-917.

18 Bass JL, Breningstall GN, Swaiman KF: Echocardiographic incidence of cardiac rhabdomyoma in Tuberous Sclerosis. A m J Cardiol 1985; 55: 1379-1382.

19 Webb DW, Osborne JP: Non-penetrance in tuberous sclerosis. J M ed G enet 1991; 28: 417-419.

20 Flinter FA, N eville BG : E xamining the parents of children with tuberous sclerosis. L ancet 1986; 2: 1167.

21 A Itman NR, Purser RK, Post MJ: Tuberous sclerosis: characteristics at CT and MR imaging. Radiology 1988; 167: 527-532.

22 A I-G azali LI, A rthur RJ, Lamb JT et al: Diagnostic and counselling difficulties using a fully comprehensive screening protocol for families at risk for tuberous sclerosis. J M ed G enet 1989; 26: 694-703.

23 Fryer $A E$, Chalmers AH, Osborne JP: The value of investigation for genetic counselling in tuberous sclerosis. J M ed G enet 1990; 27: 217-223.

24 Roach E S, Williams D P, Laster DW: Magnetic resonance imaging in tuberous sclerosis. Arch Neurol 1987; 44: 301-303.

25 Northrup H, Whelees J W, B ertin TK, Lewis R A : Variability of expression in tuberous sclerosis. J M ed Genet 1993; 30: 41-43.

26 Webb DW, O sborne J P: Tuberous sclerosis. A rch D is Child 1995; 72: 471-474.

27 Weiderholt W C, Gomez M R, Kurland LT: Incidence and prevalence of tuberous sclerosis in R ochester, $\mathrm{M}$ innesota, 1950 through 1982. Neurology 1995; 35: 600-603.

$28 \mathrm{~K}$ iribuchi $\mathrm{K}$, U chida $\mathrm{Y}, \mathrm{Fukuyama} \mathrm{Y}, \mathrm{M}$ aruyama $\mathrm{H}$ : $\mathrm{H}$ igh incidence of fundus hamartomas and clinical significance of a fundas score in tuberous sclerosis. B rain D ev 1986; 8: 509-517. 
29 Shepherd CW, Beard CM, Gomez MR, Kurland LT, Whisnant JP: Tuberous sclerosis complex in Olmsted County, Minnesota, 1950-1989. Arch Neurol 1991; 48: 400-401.

30 Stillwell TJ, Gomez MR, Kelalis DP: Renal lesions in tuberous sclerosis. J U rol 1987; 138: 477-481.

31 Van Baal J G, Fleury P, Brummelkamp WH: Tuberous sclerosis and the relation with renal angiomyolipoma. A genetic study on the clinical aspects. Clin G enet 1989; 35: 167-173.

32 Zimmerhackl LB, Rehm M, Kaufmehl K, Kurlemann G, Brandis $M$ : Renal involvement in tuberous sclerosis complex: a retrospective survey. Pediatr N ephrol 1994; 8: 451-457.

33 Jozwiak S, Pedich M, R ajszys P, M ichalowics R : Incidence of hepatic hamartomas in tuberous sclerosis. A rch Dis Child 1992; 67: 1363-1365.

34 Cheung $\mathrm{H}$, A mbrose RE, Lee PO : Liver hamartomas in tuberous sclerosis. Clin Radiol 1993; 47: 421-423.

35 Carmody $E$, Y eung EY, M CL oughlin $M$ : Liver hamartomas in tuberous sclerosis. Clin Radiol 1993; 48: 432.

36 G illberg IC, G illberg C, A hlsen G : A utistic behaviour and attention deficits in tuberous sclerosis: a population-based study. Dev Med Child Neurol 1994; 36: 50-56.

37 Bruni O, Cortesi F, Giannotti F, Curatolo P: Sleep disorders in tuberous sclerosis: a polysomnographic study. Brain Dev 1995; 17: 52-56.

$38 \mathrm{H}$ unt A, Stores G : Sleep disorder and epilepsy in children with tuberous sclerosis: a questionnaire-based study. Dev Med Child Neurol 1994;36: 108-115.

$39 \mathrm{H}$ unt A, Shepherd C: A prevalence study of autism in tuberous sclerosis. J Autism Dev Disord 1993; 23: 323-339.

$40 \mathrm{H}$ unt A : Development, behaviour and seizures in 300 cases of tuberous sclerosis. J I ntellect D isabil Res 1993; 37: 41-51.

41 Smalley SL, Tanguay PE, Smith N, Gutierrez G : A utism and tuberous sclerosis. J Autism Dev Disord 1992; 22: 339-355.

42 O sborne JP, Fryer A, Webb D : E pidemiology of tuberous sclerosis. A nn N Y A cad Sci 1991;615: 125-127.

43 Zimmerhackl LB, R ehm M, Kaufmehl K, Kurlemann G, Brandis $M L$ : Renal involvement in tuberous sclerosis complex: a retrospective survey. Pediatr N ephrol 1994; 8: 451-457.

44 Riikonon R, Simell O: Tuberous sclerosis and infantile spasms. Dev Med Child Neurol 1990; 32: 203-209.

$45 \mathrm{H}$ unt A, Dennis J: Psychiatric disorder among children with tuberous sclerosis. Dev Med Child Neurol 1987; 29: 190-198.

46 Lawlor BA, Maurer RG: Tuberous sclerosis and the autistic syndrome. Br J P sychiatry 1987; 150: 396-397.

47 Curatolo P, Cusmai R, Cortesi F, Chiron C, Jambaque I, Dulac 0 : N europsychiatric aspects of tuberous sclerosis. A nn N Y A cad Sci 1991; 615: 8-16.

48 Bundey S, E vans K : Tuberous Sclerosis: A G enetic Study. J Neurol Neurosurg Psychiat 1969; 32: 591-603.

49 Gould SR, Stewart JB, Temple L N : R ectal polyposis in tuberous sclerosis. J M ental D ef Res 1990; 34: 465-473.

50 Webb DW, Fryer AE, O sborne J P: M orbidity associated with tuberous sclerosis: a population study. Dev Med Child Neurol 1996; 38: 146-155.
51 Webb DW, Fryer A E, O sborne JP: O $n$ the incidence of fits and mental retardation in tuberous sclerosis. J M ed $\mathrm{G}$ enet 1991; 28: 395-397.

52 Webb DW, Kabala J, O sborne JP: A population study of renal disease in patients with tuberous sclerosis. $\mathrm{B} \mathrm{J}$ U rol 1994; 74: 151-154.

53 Blute ML, Malek RS, Segura JW: A ngiomyolipoma: clinical metamorphosis and concepts for management. J Urol 1988; 139: 20-24.

54 Clarke A, Webb D, O sborne JP: E arly presentation of tuberous sclerosis as bilateral renal cysts. J U rol 1995; 153: 161

55 O esterling JE, Fishman E K, G oldman SM, M arshall FF: The management of renal angiomyolipoma. J U rol 1986; 135: 1121-1124.

56 Bernstein I: R enal cystic disease in the tuberous sclerosis complex. Pediatr Nephrol 1993; 7: 490-495.

57 Stapleton FB, Johnson D, Kaplan GW, Griswold W: The cystic renal lesion in tuberous sclerosis. J Pediatr 1980; 97: 574-579.

58 Webb DW, Super M, Normand IC, O sborne JP: Tuberous sclerosis and polycystic kidney disease. BMJ 1993; 306: 1258-1259.

59 Steiner M S, G oldman SM, Fishman E K, M arshall FF: The natural history of renal angiomyolipoma. J U rol 1993; 150: 1782-1786.

60 Van B aal J G, Smiths N J, K eeman J N, L indhout D, Verhoef $S$ : The evolution of renal angiomyolipomas in patients with tuberous sclerosis. I U rol 1994; 152: 35-38.

61 Shepherd CW, Gomez M R: M ortality in the Mayo Clinic Tuberous Sclerosis Complex Study. Ann N Y Acad Sci 1991; 615: 375-377.

62 Gibbs JL: The heart and tuberous sclerosis. A $n$ echocardiographic and electrocardiographic study. $\mathrm{Br} \mathrm{H}$ eart J 1985; 54: 596-599.

63 M uhler EG, Turniski-Harder V, Engelhardt W, von B ermuth $\mathrm{G}$ : Cardiac involvement in tuberous sclerosis. $\mathrm{Br}$ H eart J 1994; 72: 584-590.

64 Jozwiak S, Kawalec W, Dluzewska J, Daszkowska J, M irkowicz-M alek M : C ardiac tumours in tuberous sclerosis: their incidence and course. Eur J Pediatr 1994; 153: 155- 157.

$65 \mathrm{~N}$ ir A, Tajik A J, Freeman WK et al: Tuberous sclerosis and cardiac rhabdomyoma. A m J Cardiol 1995; 76: 419-421.

66 Smith HC, Watson GH, Patel RG, Super M: Cardiac rhabdomyomata in tuberous sclerosis: their course and diagnostic value. Arch Dis Child 1989; 64: 196-200.

67 Torres VE, Bjornsson J, K ing BF, Kumar R, Zincke $H$, E dell $E S$, Wilson TO, Hattery R R, Gomez MR: Extrapulmonary lymphangioleiomyomatosis and lymphangiomatous cysts in tuberous sclerosis complex. $\mathrm{M}$ ayo $\mathrm{Clin} \mathrm{P}$ roc 1995; 70: 641-648.

68 Rudolph RI: Pulmonary manifestations of tuberous sclerosis. Cutis 1981; 27: 82-84.

69 Polosa $R, M$ agnano $M$, Crimi N, Vancheri C, M istretta A : Pulmonary tuberous sclerosis in a woman of child-bearing age with no mental retardation. Respir Med 1995; 89: 227-231.

70 Lie JT, Miller RD, Williams DE: Cystic disease of the lungs in tuberous sclerosis: clinicopathologic correlation, including body plethysmographic lung function tests. Mayo Clin Proc 1980; 55: 547-553. 
71 Castro M, Shepherd CW, Gomez MR, Lie JT, R yu JH: Pulmonary tuberous sclerosis. Chest 1995; 107: 189-195.

72 Westermann CJ, O ostveen AC, Wagenaar SS et al: Pulmonary tuberous sclerosis treated with tamoxifen and progesterone. Thorax 1986; 41: 892-893.

73 Slingerland J M, G rossman R F, C hamberlain D, Trembley CE: Pulmonary manifestations of tuberous sclerosis in first degree relatives. Thorax 1989; 44: 212-214.

74 K ingsley D P, K endall BE, Fitz CR : Tuberous Sclerosis: a clinicoradiological evaluation of 110 cases with particular reference to atypical presentation. Neuroradiology 1986; 28: $38-46$.

75 Braffman BH, B ilaniuk LT, N aidich TP, A Itman N R, Post MJ, Quencer RM, Zimmerman RA, Brody BA: MR imaging of tuberous sclerosis: pathogenesis of this phakomatosis, use of gadopentetate dimeglumine, and literature. Radiology 1992; 183: 227-238.

76 Frerebeau P, B enezech J, Segnarbieux F, H arbi H, D esby $A, M$ arty-D ouble $C$ : Intraventricular tumors in tuberous sclerosis. Child's N erv Syst 1985; 1: 45-48.

77 M CL aurin RL, Towbin R B: Tuberous sclerosis: diagnostic and surgical considerations. Pediat Neurosci 1985; 12: 43-48.

$78 \mathrm{Nagib}$ M G, H aines SJ, E rickson D L, M astin A R : Tuberous sclerosis: a review for the neurosurgeon. Neurosurgery 1984; 14: 93-98.

79 Conzen $\mathrm{M}$, O ppel $\mathrm{F}$ : Tuberous sclerosis in neurosurgery. A $n$ analysis of 18 patients. Acta Neurochir 1990; 106: 106-109.

80 B araitser $M$, Patton $M A$ : $R$ educed penetrance in tuberous sclerosis. J M ed Genet 1985; 22: 29-31.

81 Rott HD, Fahsold R: Tuberous sclerosis in two sibs of normal parents. Clin G enet 1991; 39: 306-308.

\section{Appendix}

\section{Tuberous sclerosis Guideline Development Group}

Ms N Bradshaw (Genetic A ssociate), Mr P Brady (Charge Nurse LD Team), Dr C Brewer (Senior R egistrar in Clinical G enetics), D r H Campbell (Public H ealth Consultant), M rs C Falconer (TS N urse, L eeds), D r D FitzPatrick (Consultant Clinical Geneticist), M rs
N Garrett (TSA Scottish Organiser), Mr G M urray (Clinical Psychologist), Dr M Porteous (Consultant Clinical G eneticist), D r F R odgers (Psychiatrist, A ssoc. Spec. Learning D ifficulties), Prof. J Stephenson (Consultant in Paediatric Neurology), Mrs D Stirling (TS Nurse, Scotland), Dr M Watson (Consultant Renal Physician)

\section{Contributors to TS Scottish Clinical Genetics Guidelines Project}

Dr P Bolton (Honorary Consultant in Child and A dolescent Psychiatry), Dr JK Brown (Consultant Paediatric Neurologist), M rs A H unt (TS Family Care Officer and Research Coordinator), Prof. R Mackie (Prof. of Dermatology), Dr RF Mueller (Consultant Clinical Geneticist), Dr M O'Regan (Neurology R esearch Fellow), Dr JP O sborne (Consultant Paediatrician), Dr W Treasurer (General Practitioner)

\section{Plus Consensus Team}

The following, most of whom work in the Clinical Genetics Centres in Scotland, attended a National Consensus Conference to discuss proposed draft guidelines.

Dr J Berg, D r D Bonthron, M rs R Cetnarskyj, M rs A Crosbie, DrY Crow, DrR Davidson, Dr J Dean, Dr D Goudie, D r H G regory, Prof. N H aites, M s J H arlen, Dr E H obson, D r S H olloway, M s L I rvine, D r A Kidd, M rs M McGill, Mrs M McJanet, Mrs L M CLeish, Dr Z Miedzabroska, Dr S Moore, Mrs D Ollis, Mrs P Pearson, M s L Preston, M sK Sarson, D r S Simpson, M r B Smith, Dr J Tolmie, D r A Trainer, M s M Van M ourik, M rs V Watters, Dr D Wilcox, Dr M Whiteford, Dr A Wright, D r D Young. 